\title{
Training and developing soft skills in higher education
}

\section{Cornalli, Federica}

\author{
University of Turin, Italy
}

\begin{abstract}
In recent decades, there has been a growing awareness of the importance of higher education to the development of a knowledge-based economy. Therefore, universities are committed to the challenge of providing students with all the skills that enable them to respond to the ever-changing needs of contemporary society and the workplace. In particular, increasing emphasis is being put on the so-called 'soft skills', viz., personal attributes and interpersonal qualities such as communication, responsiveness and the ability to work in a team. A series of studies agree in assigning soft skills a major role in employability, as well as in achieving well-being and personal goals.

Starting from a brief review of the main definitions of the notion of soft skills and how they have been classified, this paper will highlight the plurality of approaches and the critical points that characterize studies on this topic. We will then examine the role that tertiary education plays and could play in building soft skills.
\end{abstract}

Keywords: Soft skills; higher education; academic teaching. 


\section{Introduction}

The profound changes in the production system that have taken place in the last decades mostly due to pervasive technological innovation, the incessant processes of globalization and institutional transformations - call for competent and highly qualified professionals. Likewise, the transition from routine task-centered work activities to multiform and process-centered activities, as well as the growing number of people working in commerce and the service industry, creates a need for managers, supervisors and workers who are capable of positive interaction with others and can solve problems for which there is no set approach.

The need for an increasingly competent population has placed education at the center of the employability skills agenda, and in particular higher education, as it is the level where advanced professional skills are developed. Scholars, the business community, commentators and various organizations - including the Organisation for Economic Cooperation and Development (OECD), the International Labour Office (ILO) and the World Bank - place great emphasis on this level of education, recommending that countries increase the proportion of their population with tertiary level qualifications.

In Europe, higher education has expanded rapidly following the Bologna Process - an initiative to harmonize educational programs by creating a common degree structure and introducing a common credit system and quality assurance mechanism.. However, the goal of increasing the number of graduates has yet to be reached. In fact, one of the five headline targets indicated in the Europe 2020 strategy for developing a "smart, sustainable and inclusive economy delivering high levels of employment, productivity and social cohesion", is that " $40 \%$ of people aged 30-34 in the EU should have a higher education qualification". In addition to the need to increase the number of graduates, it is also necessary to improve the quality of their training to ensure that they are highly skilled and able to respond to the ever changing and complex needs of the contemporary workplace.

Numerous studies (King, 2003; Yunus and Li, 2005; Mourshed et al. 2012) have raised serious concerns about the widening gap between graduates' skills and capabilities, and the demands of the work environment in an increasingly mobile and globalized society. Recently, the European Centre for the Development of Vocational Training reported the opinions of many employers and policy-makers, who argue that these difficulties arise because of the inadequate preparation of graduates and other workers. They claim that the endemic skills mismatch in European economies results in high unemployment (CEDEFOP, 2014). Graduates often lack the ability to organize, adapt and strategically apply their specific skills to new situations and circumstances (Bridgstock 2009). The skills that are crucial to employability are not only the hard skills, i.e., cognitive and technical, job-specific and discipline-specific abilities, but also the so-called soft skills, or in other 
words transferable skills that are common to almost all complex endeavours and apply across all fields, such as communicating, problem-solving, flexibility, persistence, resilience and creativity.

This paper will discuss the notion of soft skills, starting from a review of the different definitions that have been assigned to them and a presentation of their main classifications, highlighting in particular the critical elements and the plurality of approaches involved. The role of the university in forming and developing soft skills will then be discussed.

\section{Soft skills: definitions and categorizations}

Though it is widespread in political, journalistic and popular scientific discourses, the notion of soft skills is not without problems. Nor is the terminology used for the notion uniform, as it can differ significantly from country to country. In the United Kingdom, the terms 'life skills', 'core skills' and 'key skills' are frequently used in addition, or in preference to, the term 'soft skills'. In Australia and New Zealand, expressions such as 'employability skills' or 'generic skills' are used. In the United States they prefer to talk about 'basic skills' and 'necessary skills', and in France about 'compétences transposable' and 'compétences transversales'. There is no greater convergence as regards how the concept should be defined, and in fact there are numerous definitions that take different semantic slants. Some identify soft skills mainly on the basis of what they make it possible to do, the results they make it possible to achieve. The Nobel laureate in economics James J. Heckman, in an article co-authored with Tim Kautz, states that soft skills are "personality traits, goals, motivations, and preferences that are valued in the labor market, in school, and in many other domains. [...] Soft skills predict success in life, [...] they produce that success, and [...] programs that enhance soft skills have an important place in an effective portfolio of public policies" (Heckman and Kautz, 2012, 451). Robles also focuses on the effects: "Soft skills are the intangible, non-technical, personality-specific skills that determine one's strengths as a leader, facilitator, mediator, and negotiator" (Robles, 2012, 457).

Some scholars characterize soft skills by identifying them with other attributes. In Verma's opinion (2013), soft skills correspond to the Emotional Intelligence Quotient (EQ), as opposed to the Intelligence Quotient (IQ) which concerns the hard skills. Carneiro et al. (2007) seem to equate soft skills with social skills. Lastly, other scholars believe that they represent "a dynamic combination of cognitive and metacognitive skills, interpersonal, intellectual and practical skills" (Haselberger et al. 2012, 67).

Although many critics have opined that soft skills are not clearly distinguishable because they are strongly connected to each other and interrelated to individual traits, numerous 
studies have attempted to make analytical distinctions between them and propose classifications. Among the pioneering studies in the field, mention should be made of one conducted at the beginning of the Nineties by the World Health Organization which identified the following life skills: decision-making; problem-solving, creative thinking; critical thinking; communication skills; interpersonal skills; self-awareness; empathy; coping with emotions; coping with stress (WHO 1993). A few years later, a program launched by the Swiss Federal Statistical Office, with OECD support, entitled Definition and Selection of Competencies: Theoretical and Conceptual Foundations (De.Se.Co) provided a conceptual framework to inform the identification of competencies needed to lead a personally and socially worthwhile life in a contemporary democratic state. This study, which was grounded in a holistic model of competence and drew on contributions from experts in disciplines such as sociology, anthropology, philosophy, psychology and economics, identified three categories of key competencies: interacting in socially heterogeneous groups (which includes the ability to relate well to others, cooperate, and manage and resolve conflicts); acting autonomously (which includes competencies that empower individuals to manage their lives in meaningful and responsible ways by exercising control over their living and working conditions, e.g., the ability to form and conduct life plans and personal projects, and to defend and assert rights, interests, limits and needs) and using tools interactively (which includes the ability to use language, symbols, text, knowledge, information and technology interactively) (Rychen and Salganik 2001).

Other classifications were subsequently proposed by the European Union (Key Competences for Lifelong Learning, EU 2006), by the OECD (21 ${ }^{\text {st }}$ century skills, 2009) and by internationally renowned scholars (Goleman and Boyatzis, 2008; Ciappei and Cinque, 2014).

The wide variety of classifications stems from the fact that they were formulated using multiple reference criteria. For example, some soft skills have been identified by grouping them into two clusters: interaction skills and motivation skills (Moss and Tilly 2001), others have been identified with reference to a matrix whose rows are the different areas of competences (cognitive, realization, social, emotional) and whose columns are the different organizational roles (operational, manager, executive) (Manpower Group 2014), and many other criteria could also be mentioned. There are also various ways of constructing these classifications. For example, some were drafted from an 'employers' perspective' by surveying business executives or human resource managers regarding the needs of the labor market — as, for example, Robles (2012) and Career Builder (2014) — while others derive from an 'institution perspective' or 'expert perspective' because they report the orientations of national, international or supranational institutions and the opinions of scholars from different disciplines (as for example in the De.Se.Co project mentioned above). This results in dissimilar outcomes. While the first perspective identifies characteristics and capacities 
that are directly related to individual productivity, which leads to mainly economic benefits, the latter also identifies skills that promote sustainable development and facilitate the creation of social cohesion. Despite their number and variety, these classifications are undoubtedly valuable. They provide a systematic and rationally ordered list of attributes that would otherwise be a formless mass. However, these classifications should not be reified. Although useful as simple work tools, they require continuous maintenance: there are countless soft skills and classifications must be revised and expanded to reflect constant changes in technology.

\section{Soft skills in higher education}

The education system's persistent misalignment with the needs of the labor market raises doubts about the university and its role in forming the skills needed to lead a successful and responsible life and for society to face present and future challenges.

Accordingly, as part of the Qualifications Framework of the European Higher Education Area, the European Union member states have adopted a set of "cycle or level descriptors" in order to establish typical expectations of achievements the end of each of the three Bologna cycles. These descriptors, the so-called Dublin Descriptors, are generic statements that describe the expected results not in terms of knowledge learned, but in terms of levels of competence achieved. They include the following five components: knowledge and understanding, applying knowledge and understanding, making judgements, communication, and lifelong learning skills. In an attempt to identify the nature of the whole qualification, the descriptors are not subject-specific or limited to academic, professional or vocational areas, but focus on the acquisition of transferable skills, effectively incorporating the most recent research guidelines that emphasize the importance of soft skills in achieving expected performance levels. Academic teaching is thus faced with a complex challenge. On the one hand, it seems easier to transmit attributes that involve personal characteristics in the family or in the early levels of education, when growing children are most receptive. On the other hand, university teaching practice is often still pervaded by the lecturing method and traditional approaches. In recent times, the growing interest in this topic - coupled with the multiplication of recommendations by various institutions (e.g. EU, OECD) in favor of training and developing soft skills as well as the need for competitive educational provision that meets the requirements of the job market - has meant that most universities are introducing soft skills initiatives. The catalog of proposals is very wide and varies considerably in terms of student involvement and personalization. It ranges from simply posting written materials or videos on the university website, up to the preparation of coaching and tutoring programs. Over and above the different possible approaches, the question that arises is whether soft skills 
should be taught in a specific separate module, or if they should be developed in each of the disciplines making up the regular curriculum. In the latter case, faculty should encourage the use of different teaching methods to develop graduate attributes in their students. In particular, teaching should take a holistic, learner-centered and problem-based approach and should include educational activities such as work teams, case studies, simulations, project works and presentations from the students. The teacher should also assume multiple roles, such as mentor, facilitator and evaluator, thus demonstrating and modelling the utility of possessing generic skills (B-HERT 2002).

\section{Conclusions}

Recent changes in the production system and labor market have placed higher education under increasing pressure to train employable graduates. In order to achieve this purpose, universities must not only transmit knowledge and abilities that are specific to each discipline or occupation, but must also develop so-called soft skills, meaning dispositions and attributes that are transferable to many occupational situations and areas.

Faced with this need, now considered essential, efforts to build soft skills and implement them effectively must be redoubled. In this connection, it seems necessary to establish a robust framework of soft skills based on theoretical and empirical research. Though there are numerous studies on this subject, soft skills are constantly changing properties and require constant redefinition. Moreover, a further issue deserves attention: while a distinctive feature of soft skills is the fact that they cut across many fields of application, it is known that they can take on different characteristics across cultures and settings. Investigating the various contexts of use and methods of application could provide useful insights.

Lastly, continuing research on soft skills can avert the risk of reductionism, or in other words, considering only the labor market outcomes while neglecting the important positive effects on health, family life, social cohesion, civic engagement and life satisfaction.

\section{References}

B-HERT Business-Higher Education Roundtable (2002). Enhancing the learning and employability of graduates: the role of generic skills. B-HERT Position Paper, No. 9.

Bridgstock, R. (2009) The graduate attributes we've overlooked: enhancing graduate employability through career management skills. Higher Education Research \& Development, 28, 1, 31-44. 
Bologna Working Group (2005). A Framework for qualifications of the European higher education area. Bologna Working Group Report on Qualifications Frameworks, Copenhagen, Danish Ministry of Science, Technology and Innovation.

Career Builder (2014). Overwhelming majority of companies say soft skills are just as important as hard Url: www.careerbuilder.com/share/aboutus/pressreleasesdetail.aspx?sd=4/10/20 14\&id=pr817\&ed=12/31/2014.

Carneiro, P., Crawford, C., Goodman, A. (2007). The impact of early cognitive and noncognitive skills on later outcomes. London: Centre for the Economics of Education, London School of Economics.

CEDEFOP (2014). Skill mismatch: More than meets the eye. Briefing Note, March 2014. Thessaloniki: European Centre for the Development of Vocational Training. Url: www.cedefop.europa.eu/en/publications-and-resources/ publications/9087.

Ciappei C., Cinque M. (2014). Soft skills per il governo dell'agire. Milano: FrancoAngeli.

European Union (2006). Recommendation of the European Parliament and of the Council of 18 December 2006 on key competences for lifelong learning. Url: http://eurlex.europa.eu/legal-content/EN/TXT/?uri=celex\%3A32006H0962.

Goleman D., Boyatzis R. (2008). Social intelligence and the biology of leadership. Harvard Business Review, September, 74-81.

Haselberger, D., Oberhuemer, P., Pèrez, E., Cinque, M., Capasso D. (2012). Mediating soft skills at higher education institutions, handbook of the ModES project: Lifelong learning programme, http://www.euca.eu/en/prs/modes-handbook.aspx.

Heckman, J.J., Kautz, T. (2012). Hard evidence on soft skills. Labour Economics, 19(4), 451-464.

King, Z. (2003). New or traditional careers? A study of UK graduates' preferences. Human Resource Management 13(1), 5-27.

Manpower Group (2014). Soft skills for talent, internal report. Url: www.manpowergroup.it/indagine-soft-skills-manpowegroup

Moss, P., Tilly, C. (2001). Stories employers tell: Race, skill and hiring in America. New York: Russell Sage.

Mourshed, M., Farrell, D., Barton, D. (2012). Education to employment: Designing a system that works. Washington, DC: McKinsey Center for Government.

OECD (2009). 21 $1^{\text {st }}$ Century skills and competences for new millennium learners in OECD countries. EDU Working paper no. 41 by Ananiadou K., Claro, M.

Robles, M.M. (2012). Executive perceptions of the top 10 soft skills needed in today's workplace. Business Communication Quarterly, 75(4), 453-465.

Rychen, D.S., Salganik, L.H. (eds) (2001). Definition and selection of key competencies. Gottingen: Hogrefe \& Huber Publishers.

Verma, S. (2013). Enhancing employability @ soft skills. Chandigarth-Delhi-Chennai: Pearson.

WHO (1993). Life skills education in schools. Genève: WHO.

Yunus, K., Li, S. (2005). Matching job skills with needs. Business Times (1 October). 